\section{El monte \\ Olimpo, el río Támesis y la playa de Cannes}

Luis Velezmoro a publicidad siempre ha ido de la mano con el desarrollo de las economías de los pueblos y se ha valido de innumerables estrategias y medios para persuadir al consumidor. Las señales más antiguas las encontramos en Egipto, Grecia y Roma, donde ya empleaban medios como las estelas, los pregoneros y los rótulos. Es famoso Estentor, el animador griego que anunciaba a los ganadores de los juegos olímpicos, cuya voz, dice la leyenda, superaba a la de 50 hombres juntos, de ahí que el adjetivo estentóreo proviene de ese hecho.

Es conocido también que los griegos desarrollaron mercados enormes, que como el de Trajano en Roma, sirvieron para comercializar miles de productos en espacios comparables con los grandes shopping centers de Estados Unidos. Imagínense un mercado solo para vender perfumes como el Megalópolis de Grecia.

Siglos después el imperio de la publicidad se instala en Londres, donde la creatividad sigue impresionando a la humanidad toda. Los ingleses son los pioneros en una serie de técnicas y medios para llegar al consumidor, como el hombre sándwich, que cual ambulante o pregonero gráfico camina entre los clientes; hicieron la primera campaña de bien público para luchar contra la peste y desarrollaron la primera estrategia de merchandising para promover, vía muñecos, sombreros y bastones, los libros de Charles Dickens. 
La creatividad publicitaria manifestada en estas culturas fue la base de la era moderna de la publicidad, donde el cine estaba en la cresta de la ola y era muy bien aprovechado para hacer publicidad y propaganda, ya que la fórmula mágica de imagen y sonido y a luz apagada cautivaron a la audiencia.

En Europa, durante los años cincuenta, existían numerosas salas con asistencia regular de mucho público que iba a ver sus películas y actores preferidos $y$, de paso, disfrutaba de anuncios publicitarios fijos y filmados por realizadores con experiencia de cineastas. Fue así que ya existían dos asociaciones internacionales de cine publicitario: ISAS, integrada por Ernest Pearl, Jacques Zadoc, Jo Linten y Enrico Martini, y la ISPA, a la que pertenecían Jean Mineur, Bill Annmet y Massimo Momigliano. Ambas instituciones se unieron y organizaron el primer festival en junio de 1952 en Venecia, que tuvo como objetivo mostrar el cine publicitario como un medio poderoso para promover la venta de productos y servicios. Fue tan grande el éxito de este primer evento que decidieron cambiar la sede cada año. El de 1954 fue en Montecarlo, al año siguiente fue en Cannes y en 1956 fue nuevamente en Venecia.

Años más tarde las asociaciones se juntaron, uniéndose también cineastas publicitarios de todo el mundo, espe- cialmente de Japón, Argentina, Sudáfrica, etcétera, y nació SAWA (Screen Advertising World Association) para coordinar y seleccionar los anuncios publicitarios para el festival.

La organización, más consolidada, decidió que las sedes sean Cannes y Venecia, estableció los reglamentos y jurados y resolvió que la Palma y el León sean los trofeos, que reemplazaron a las copas tradicionales usadas en cualquier competencia. A partir de 1971 la sede se fijó en Cannes, debido a problemas de organización y económicos que surgieron en Italia y solo en 1983 el festival volvió a Venecia para luego continuar en Francia hasta la fecha.

En los años ochenta, a sugerencia de Estados Unidos y por la presión de jóvenes publicitarios de todo el mundo, se incorporó la categoría de televisión a regañadientes de los organizadores, que eran defensores de la pureza del festival que había sido creado exclusivamente para cine publicitario. Los comerciales se exhibían en vídeo y cine, con monitores apostados al costado de la sala de proyección del viejo palacio, templo del festival.

En 1990 de incluyó la categoría Press \& Poster para mostrar los mejores anuncios impresos. En los últimos años se han incorporado las categorías de Cyber Lions para premiar lo mejor en nuevas tecnologías e internet. 


\section{La marca Cannes}

Así como los cineastas del mundo aspiran obtener un Oscar de Hollywood, los publicitarios, incluidos jóvenes creativos y estudiantes, sueñan ser "tocados" por los leones de Cannes. El hecho de ser finalista en cualquier categoría constituye un honor para sus creadores, pues se cuenta por miles la cantidad de obras en concurso.

Evidentemente, el festival ha evolucionado desde su origen como un encuentro entre destacados cineastas publicitarios, a un evento que congrega a lo mejor de la industria publicitaria mundial. Al comienzo los jurados no pasaban de siete miembros, actualmente son más de 60 personas reunidas por categorías, quienes inicialmente hacen una preselección denominada short-list, luego evalúan las mejores piezas y determinan los ganadores de los leones de Bronce, Plata y Oro.

Existe el Grand Prix, que es elegido entre todos los ganadores del León de Oro, exceptuando las categorías de campañas sociales y obras benéficas. También existe un premio a la agencia del año, al anunciante del año, otro otorgado por la prensa y en el 2003, para el 50 aniversario del festival, han incorporado el León de Titanio, destinado a aquella campaña que, independientemente de su categoría, represente una verdadera innovación publicitaria por su idea, creación, desarrollo, etcetera.
En el 2003 participaron más de 16.000 piezas provenientes la mayoría de Estados Unidos, Alemania, Inglaterra, Brasil, España, Australia, Japón y Francia. Cabe mencionar que algunas piezas ganadoras son las denominadas "truchos", aquellas que son producidas solo para concursar, cumpliendo los requisitos mínimos de difusión y a veces sin el consentimiento del anunciante. Tanto los organizadores como el jurado tienen mucho cuidado en la selección, y si descubren que es un anuncio fraudulento, censuran al ganador y le hacen devolver el trofeo.

El valor que tiene un galardón para una agencia es posibilitarle mayor cantidad de anunciantes y para este último le genera publicity a escala mundial. La industria publicitaria, por su parte, tiene en Cannes la oportunidad de ver y analizar la evolución de la creatividad publicitaria generada por los estrategas más brillantes del planeta.

\section{Bibliografía}

Asociación Española de Editores de Publicaciones Periódicas. El publicista. Madrid, junio del 2003.

MOLINÉ, Marcel. La fuerza de la publicidad. Madrid: McGraw-Hill, 2000 . 